\title{
Erratum to: Methylome Evolution in plants
}

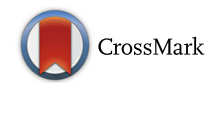

Amaryllis Vidalis ${ }^{1 \dagger}$, Daniel Živković ${ }^{2 \dagger}$, René Wardenaar $^{3}$, David Roquis ${ }^{1}$, Aurélien Tellier ${ }^{2 *}$ and Frank Johannes ${ }^{1,4^{*}}$

\section{Erratum}

After publication of this article [1] we noticed that the centromere of Chromosome 3 was missing from Fig. 4a, and that the Fig. 4e y-axis should read 'CG meth. Div. W-Acc.'. The y-axis of the barplot in Fig. 5a should read 'Number of cytosines'. The corrected Figs. 4 and 5 are shown below.

\begin{abstract}
Author details
${ }^{1}$ Population Epigenetics and Epigenomics, Technical University of Munich, Liesel-Beckman-Str. 2, 85354 Freising, Germany. ${ }^{2}$ Population Genetics,

Technical University of Munich, Liesel-Beckman-Str. 2, 85354 Freising, Germany. ${ }^{3}$ Groningen Bioinformatics Centre, University of Groningen, 9747 AG Groningen, The Netherlands. ${ }^{4}$ Institute for Advanced Study, Technical University of Munich, Lichtenbergstr. 2a, 85748 Garching, Germany.
\end{abstract}

Received: 19 February 2017 Accepted: 19 February 2017

Published online: 27 February 2017

\section{Reference}

1. Vidalis A, Živković D, Wardenaar R, Roquis D, Tellier A, Johannes F.

Methylome evolution in plants. Genome Biol. 2016;17:264.

\footnotetext{
*Correspondence: tellier@wzsw.tum.de; frank@johanneslab.org

${ }^{\dagger}$ Equal contributors

2Population Genetics, Technical University of Munich, Liesel-Beckman-Str. 2, 85354 Freising, Germany

'Population Epigenetics and Epigenomics, Technical University of Munich, Liesel-Beckman-Str. 2, 85354 Freising, Germany
} 


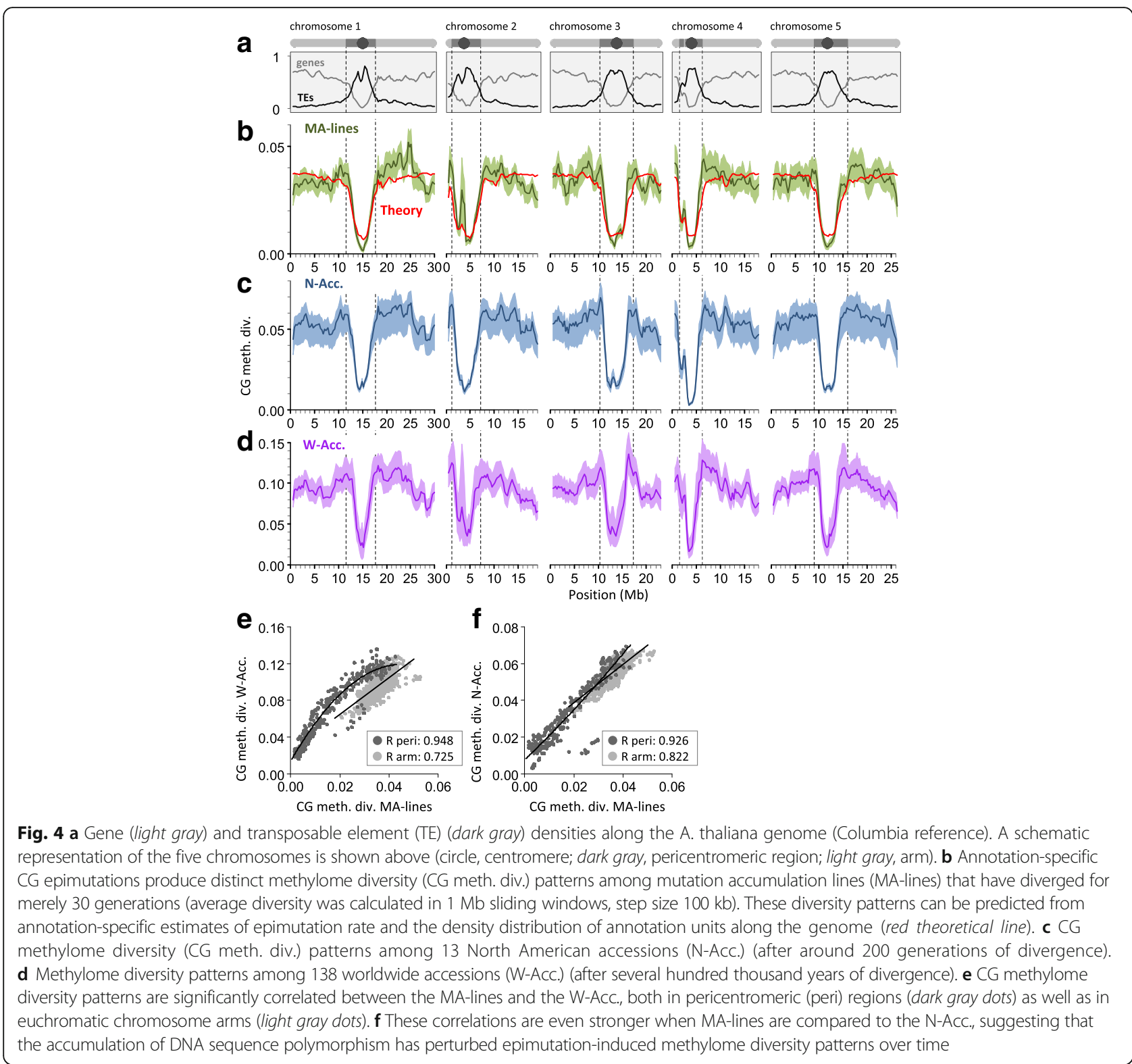


a

\section{Cytosines}

$\begin{array}{lllllllll}\text { Acc. } 1 & M & M & M & U & M & U & U & U\end{array}$

$\begin{array}{llllllllll}\text { Acc. } 2 & \mathrm{M} & \mathrm{U} & \mathrm{M} & \mathrm{U} & \mathrm{M} & \mathrm{M} & \mathrm{U} & \mathrm{U}\end{array}$

$\begin{array}{lllllllll}\text { Acc. } 3 & M & \text { U } & M & \text { U } & M & M & \text { U } & \text { U }\end{array}$

$\begin{array}{lllllllll}\text { Acc. } 4 & M & \text { U } & \text { U } & \text { U } & \text { U } & M & \text { U } & \text { M }\end{array}$

$\begin{array}{lllllllll}\text { Acc. } 5 & M & U & M & M & U & M & U & U\end{array}$

Counts

$\begin{array}{lllll}4 & 1 & 4 & 2 & 1\end{array}$

4

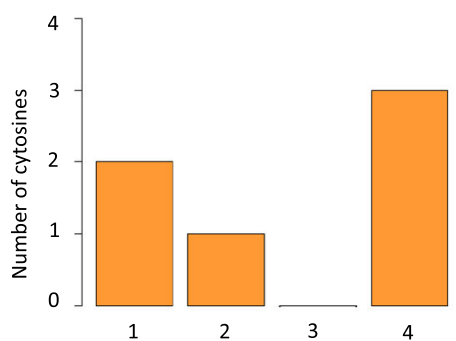

b

Number of unmethylated alleles

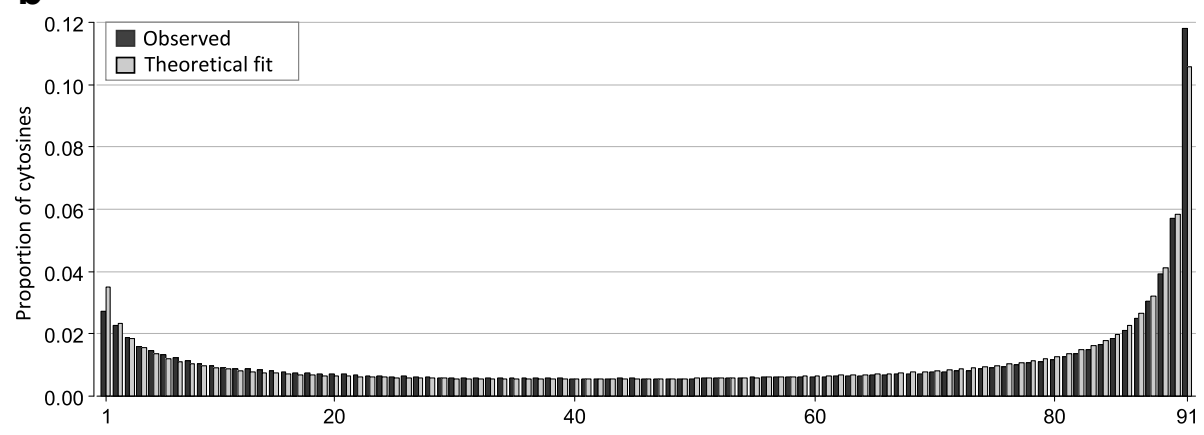

Number of unmethylated alleles

Fig. 5 a Simplification of the reconstruction of a methylation site frequency spectrum (mSFS). In this example, we consider a sample size of five accessions (Acc.), and eight sites among which two (in gray) are monomorphic and thus discarded for the mSFS. For each cytosine, each accession might exhibit a methylated (M) or an unmethylated (U) state. For the mSFS, counts are taken of the number of accessions that are unmethylated for that cytosine. These counts define discrete epiallelic classes (number of unmethylated alleles). $\mathbf{b}$ The observed frequencies of each epiallelic class is determined, in this case, from genic CG sites of 92 A. thaliana worldwide natural accessions (red bars), along with the maximum likelihood estimate based on the theoretical result of Charlesworth and Jain [123] (pink bars). The theoretical model (see Box 1) provides an accurate fit to the observed genic CG methylation diversity patterns, suggesting that CG epimutations are a major factor in shaping methylome diversity in natural populations of A. thaliana over evolutionary timescales 